\title{
PERSEPSI APARATUR SIPIL NEGARA TERHADAP PENGGUNAAN JASA BANK SYARIAH (STUDI PEGAWAI KANTOR KEMENTERIAN AGAMA KABUPATEN LOMBOK TIMUR)
}

\author{
IMAMUDDIN ${ }^{1}$ \\ ${ }^{1}$ Universitas Islam Negeri Mataram \\ email: imamuddiin0@gmail.com
}

\begin{abstract}
The purpose of this study in general is to determine the perception of state civil servants choosing to use the services of Islamic banks in employees at the Office of the Ministry of Religion in East Lombok. This type of research is classified as field research, with the research approach used is phenomenology. The source of this research data is the state civil service users of Islamic bank services. Next, the data collection methods used were interviews and documentation. Furthermore, data processing and analysis techniques are carried out through four stages, namely: data collection, data reduction, data presentation, and drawing conclusions. The results of the study concluded that basically the state civil apparatus has perceptions of Islamic bank services seen from knowledge and attitudes because of the services provided by Islamic banks and also mild administrative costs. The perception factor of employees of the state apparatus in using bank services both Islamic banks cannot be separated from the busaya of the organization where the employee works. The main employees of the state civil servants in the office of the Ministry of Religion in East Lombok Regency use the services of conventional banks because there are rules from superiors in uniforming accounts in receiving employee salaries.
\end{abstract}

Key words: perception, ASN, Islamic Bank.

\begin{abstract}
ABSTRAK
Tujuan penelitian ini secara umum adalah untuk mengetahui persepsi aparatur sipil negara memilih menggunakan jasa bank syariah pada pegawai di Kantor Kementerian Agama Lombok Timur. Jenis penelitian ini tergolong penelitian lapangan (field research), dengan pendekatan penelitian yang digunakan adalah fenomenologi. Adapun sumber data penelitian ini adalah aparatur sipil negara pengguna jasa bank syariah. Selanjutnya, metode pengumpulan data yang digunakan adalah wawancara dan dokumentasi. Selanjutnya, teknik pengolahan dan analisis data dilakukan dengan melalui empat tahapan, yaitu: pengumpulan data, reduksi data, penyajian data, dan penarikan kesimpulan. Hasil penelitian menyimpulkan bahwa pada dasarnya aparatur sipil negara memiliki persepsi terhadap jasa bank syariah dilihat dari pengetahuan dan sikap karena pelayanan yang diberikan bank syariah dan juga biaya administrasi yang ringan. Faktor persepsi pegawai aparatur negara dalam menggunakan jasa bank baik bank syariah tidak lepas dari budaya organisasi di mana pegawai tersebut bekerja. Utamanya pegawai aparatur sipil negara di kantor Kementerian Agama Kabupaten Lombok Timur menggunakan jasa bank konvensional karena telah ada aturan dari atasan dalam penyeragaman rekening dalam penerimaan gaji pegawai.
\end{abstract}

Kata Kunci: persepsi, ASN, Bank Syariah 


\section{A. PENDAHULUAN}

Indonesia merupakan negara dengan sebagian besar penduduknya muslim. Namun hal ini belum cukup membuat bank-bank syariah menjadi bank yang besar di Indonesia karena minat masyarakat yang masih kurang. Bank syariah seolah sulit menembus dominasi perbankan konvensional, padahal mayoritas masyarakat Indonesia adalah muslim. Hal ini disebabkan perkembangan sektor perbankan tidak terlepas dari perilaku konsumen dalam menentukan pilihannya dalam menggunakan jasa bank, pilihan akan menggunakan jasa bank syariah atau jasa bank konvensional yang telah dulu memainkan perannya di industri perbankan Indonesia.

Sebagai negara dengan jumlah penduduk muslim terbesar di dunia, institusi bank di Indonesia ditantang untuk dapat menggunakan sistem bank yang berbasiskan kepada syariah Islam. Meskipun agak terlambat, setelah beberapa dekade dibahas oleh para ulama dan pemerintah tentang persoalan halal dan haramnya bunga dalam perbankan, tahun 1992 dikeluarkan Undang-Undang No. 7 tahun 1992 tentang Perbankan yang menjadi tonggak legalitas diadopsinya perbankan syariah dalam sistem perbankan di Indonesia. Peraturan ini kemudian diperbaiki dengan UndangUndang No. 10 tahun 1998, lalu UndangUndang No. 23 tahun 1999, dan terakhir dengan Undang-Undang No. 3 tahun 2004 tentang Bank Indonesia.

Industri perbankan syariah telah mengalami perkembangan yang pesat. Dengan diterbitkannya Undang-Undang No. 21 Tahun 2008 Tentang Perbankan Syariah tertanggal 16 Juli 2008, pengembangan industri perbankan syariah nasional semakin memiliki landasan hukum yang memadai dan akan mendorong pertumbuhannya secara lebih cepat lagi. Perkembangan bank syariah mengalami peningkatan. Dengan demikian, peran industri perbankan syariah dalam mendukung perekonomian nasional semakin signifikan dari waktu ke waktu.

Industri perbankan yang pertama menggunakan sistem syariah adalah PT Bank Muamalat Indonesia tbk yang didirikan pada tahun 1991 dan memulai operasionalnya pada bulan Mei 1992. Pendirian bank dimaksud, diprakarsai oleh Majelis Ulama Indonesia (MUI), Pemerintah Indonesia serta mendapat dukungan nyata dari eksponen Ikatan Cendekiawan Muslim se-Indonesia (ICMI) dan beberapa pengusaha muslim. 
Selain itu, pendirian Bank Muamalat ini juga mendapat dukungan dari masyarakat Indonesia yang dibuktikan dengan komitmen pembelian saham Perseroan senilai Rp 84 Miliar pada saat penandatanganan akta pendirian Perseroan.

Kehadiran bank syariah di tengahtengah perbankan konvensional untuk menawarkan sistem perbankan alternatif bagi umat Islam yang membutuhkan atau ingin memperoleh layanan jasa perbankan tanpa harus melanggar larangan riba. Sebagaimana disebutkan oleh para ekonom muslim, ada dua alasan utama mengenai latar belakang berdirinya bank syariah, yaitu: (1) adanya pandangan bahwa bunga (interest) pada bank konvensional hukumnya haram karena termasuk dalam kategori riba yang dilarang dalam agama; (2) dari aspek ekonomi, penyerahan risiko usaha terhadap salah satu pihak dinilai melanggar norma keadilan dan dapat menimbulkan rasa mementingkan diri sendiri. Dalam jangka panjang sistem perbankan konvensional akan menyebabkan penumpukan kekayaan pada segelintir orang yang memiliki kapital besar.

Tidak bisa dipungkiri bahwa Aparatur Sipil Negara (ASN) merupakan tulang punggung pemerintahan dalam menyelenggarakan pemerintahan dan pembangunan untuk mencapai tujuan nasional seperti yang telah diamanatkan dalam pembukaan UUD 1945, yaitu melindungi segenap bangsa Indonesia dan seluruh tumpah darah Indonesia dan untuk memajukan kesejahteraan umum, mencerdaskan kehidupan bangsa dan ikut melaksanakan ketertiban dunia yang berdasarkan kemerdekaan, perdamaian abadi dan keadilan sosial.

Mengingat bahwa masyarakat di Kabupaten Lombok Timur mayoritas beragama Islam, maka hal ini akan berimplikasi terhadap perkembangan perbankan syariah dengan dukungan dari umat Islam itu sendiri. Pertumbuhan perbankan syariah sampai saat ini, khususnya bank syariah yang ada di Kabupaten Lombok Timur semakin meningkat terlihat perkembangan jumlah bank syariah dari tahun ke tahun semakin bertambah.

Sebagai unsur aparatur abdi negara dan abdi masyarakat, yang penuh kesetiaan dan ketaatan kepada pancasila, UUD 1945, negara dan pemerintahan melaksanakan tugas pemerintahan dan pembangunan tentu saja mempunyai hakhak dalam melaksanakan tugas. Hak paling dekat dan dibutuhkan oleh 
aparatur sipil negara ialah memperoleh gaji yang layak sesuai dengan pekerjaan dan tanggung jawabnya, mendapatkan cuti sesuai dengan peraturan yang berlaku, memperoleh perawatan jika ditimpa sesuatu kecelakaan dalam menjalankan kewajiban, memperoleh tunjangan jika menderita cacat jasmani atau cacat rohani dalam menjalankan tugas dan kewajibannya yang menyebabkan tidak dapat bekerja lagi, keluarganya memperoleh uang duka jika pegawai tersebut meninggal, berhak atas pensiun jika telah memenuhi syarat yang ditentukan.

Persepsi aparatur sipil negara terhadap bank syariah cukup beragam, baik mengenai bunga bank, sistem bagi hasil, jual beli dan sewa, demikian juga dengan pengetahuan dan sikap aparatur sipil negara di Kabupaten Lombok Timur terhadap bank syariah, berbagai pengetahuan dan sikap yang muncul dengan berbagai alasan. Oleh karena itu, perkembangan bank syariah perlu mendapatkan perhatian dari seluruh pihak terkait, baik dari pihak akademisi maupun dari pihak praktisi demi pengembangan bank syariah di masamasa yang akan datang.

Struktur pengetahuan dan sikap aparatur sipil negara yang sudah terbangun sekian lama tersebut, tentu saja tidak mudah untuk diarahkan kepada hanya perbankan yang berdasarkan syariah Islam. Dengan alasan itu, penelitian ini dirasa penting untuk mengungkapkan struktur persepsi aparatur sipil negara saat ini, serta faktorfaktor yang menimbulkan persepsi untuk diubah agar lebih menerima bank syariah.

Sikap masyarakat terhadap bunga dan bagi hasil yang beragam, sebagian masyarakat tetap menerima bunga, sebagian menerima sistem bagi hasil dengan tetap menerima bunga, dan sebagian lagi menolak bunga sehingga dari berbagai sikap ini memberikan nuansa yang cukup menarik sebagai gambaran tentang persepsi aparatur sipil negara dalam menyikapi perbankan syariah. Di Kantor Kementerian Agama Kabupaten Lombok Timur ini aparatur sipil negara melihat fenomena ini terjadi sesuai dengan prinsip syariah atau sebatas argumen saja karena tentunya para pegawai ASN itu sudah tidak asing lagi dengan keberadaan bank syariah tetapi melalui observasi yang peneliti lakukan secara tidak langsung dengan salah satu pegawai, pegawai tersebut kebetulan sama sekali tidak menggunakan jasa bank syariah dengan alasan beranggapan sama saja antara 
perbankan syariah dengan konvensional.

\section{B. TINJAUAN PUSTAKA}

Anita Rahmawaty, Jurnal ADDIN Vol. 8. No. 1 Februari 2014 dengan Judul, "Pengaruh Persepsi tentang Bank Syari'ah terhadap Minat Menggunakan Produk di BNI Syariah Semarang”. Hasil penelitian ini menyimpulkan pertama, persepsi tentang bunga bank berpengaruh secara positif dan signifikan terhadap minat menggunakan produk bank syariah. Kedua, persepsi tentang sistem bagi hasil berpengaruh secara positif dan signifikan terhadap minat menggunakan produk bank syariah. Ketiga, persepsi tentang produk Bank Syariah tidak berpengaruh terhadap minat menggunakan produk Bank syariah.

Suparno. Jurnal Telaah \& Riset Akuntansi Vol. 2, No. 1. Januari 2009 dengan Judul, Persepsi Mahasiwa Fakultas Ekonomi Universitas Syiah Kuala terhadap Perbankan Syariah sebagai Lembaga Keuangan Syariah ${ }^{e}$. Hasil penelitian tersebut disimpulkan bahwa mahasiswa Fakultas Ekonomi Universitas Syiah Kuala mempersepsikan positif perbankan syariah sebagai lembaga keuangan syariah.

Harviz Akbar dan Haroni Doli H. Ritonga. Jurnal Ekonomi dan Keuangan,
Vol. 1, No. 2, Januari 2013. Dengan Judul ,Persepsi Etnis China terhadap Perbankan Syariah di Kota Medan`. Hasil penelitian ini menyimpulkan bahwa hasil regresi menunjukkan bahwa pekerjaan, pelayaan, promosi dan bukti fisik mempengaruhi persepsi etnis Cina terhadap perbankan syariah di Kota Medan dengan signifikasi pada alpa 5\%. Berdasarkan pernyataan terhadap variabel persepsi terlihat bahwa masyarakat etnis Cina tidak mengetahui seluk beluk perbankan syariah sehingga menghasilkan persepsi yang kurang memuaskan terhadap perbankan syariah untuk itu diperlukan peningkatan seminar-seminar mengenai produkproduk, prinsip dan mekanisme kerja bank Syariah.

\section{METODE PENELITIAN}

Lokasi penelitian ini dilakukan di Kantor Kementrian Agama kabupaten Lombok Timur. Penelitian ini adalah penelitian lapangan (field research), yaitu melakukan penelitian langsung ke lokasi untuk mendapatkan dan mengumpulkan data-data. penelitian ini bersifat deskriftif kualitatif. Yang diarahkan pada penelitian studi kasus, yakni penelitian yang meneliti fenomena kontemporer secara utuh dan menyeluruh pada kondisi 
yang sebenarnya, dengan menggunakan berbagai bentuk data kualitatif. Penjelasan tersebut menunjukkan bahwa, karakteristik penelitin studi kasus pada umumnya sama dengan karakteristik penelitian kualitatif pada umumnya. Secara khusus, penelitian studi kasus memiliki karakteristik yang berbeda dibandingkan dengan jenis penelitian kualitatif yang lain. Kekhususan penelitian studi kasus adalah pada cara pandang penelitiannya terhadap obyek yang diteliti.

Pendekatan yang digunakan dalam penelitian ini yaitu pendekatan fenomonologi. Fenomenologi merupakan suatu metode penelitian yang kritis dan menggali fenomena yang ada secara sistematis. Tujuan dari penelitian dengan pendekatan fenomenologi adalah mengembangkan makna pengalaman hidup dari suatu fenomena dalam mencari kesatuan makna dengan mengidentifikasi inti fenomena dan menggambarkan secara akurat dalam pengalaman hidup sehari-sehari.

Data adalah serangkaian informasi, bukti dan atau keterangan atas suatu objek yang memiliki karakteristik tertentu (Teguh, 2014). Data yang digunakan dalam penelitian ini adalah data sekunder dan primer. Data primer adalah data yang dikumpulkan dan diolah dendiri oleh penelti. (Soeratno dan Lincolin, 2008).

Untuk mendapatkan data yang akurat dan valid, maka peneliti menggunakan beberapa metode pengumpulan data yaitu: 1) Observasi (pengamatan), Observasi merupakan salah satu teknik dalam pengumpulan data. Observasi adalah mengumpulkan data di lapangan secara langsung. Data observasi salah satunya adalah interaksi dalam suatu organisasi atau pengalaman kerja karyawan dalam berorganisasi. (Raco, 2010). Adapun dalam penelitian ini Observasi (pengamatan) dilakukan terhadap Kinerja Dinas Koperasi Dan UKM NTB Dalam Pembinaan Koperasi Di Nusa Tenggara Barat. 2) Interview (wawancara), Wawancara yaitu berbicara atau bercakap-cakap dengan tujuan tertentu, biasanya dilkakukan oleh lebih dari satu orang, yaitu pewawancara yang disebut dengan interviewer yaitu yang mengajukan pertanyaan-pertanyaan dan yang menjawab atau yang memberikan jawaban atas pertanyaan tersebut disebut dengan interviewee.(J. Moleong, 2017). Adapun dalam penelitian ini wawancara yang dilakukan yaitu tentang Kinerja Dinas Koperasi Dan UKM NTB Dalam Pembinaan Koperasi Di Nusa Tenggara 
Barat. 3) Dokumentasi merupakan salah satu teknik pengumpulan data atas dokumen-dokumen berupa rekaman atas kejadian masa lalu yang dicetak dalam bentuk hard copi, sutar, buku, arsip, serta dokumen-dokumen lainnya.(Djam'an Satori dan Aan Komariah, 2014).

Instrumen penelitian merupakan alat bantu yang amat penting dan strategis kedudukannya dalam keseluruhan kegiatan penelitian, karena data yang diperlukan untuk menjawab rumusan masalah penelitian diperoleh melalui instrumen. Berikut instrumen yang peneliti gunakan, yaittu: 1) Observasi adalah Pengamatan obyek penelitian baik dengan cara sebagai partisipan secara langsung maupun tidak langsung kemudian dicatat secara urut. Peneliti mengamati kegiatan sehari-hari yang dilakukan oleh obyek penelitian. (Sugiyono, 2016). 2) Interview (wawancara), Wawancara yaitu berbicara atau bercakap-cakap dengan tujuan tertentu, biasanya dilkakukan oleh lebih dari satu orang, yaitu pewawancara yang disebut dengan interviewer yaitu yang mengajukan pertanyaan-pertanyaan dan yang menjawab atau yang memberikan jawaban atas pertanyaan tersebut disebut dengan interviewee. (J. Moleong, 2017). 3) Dokumentasi merupakan salah satu teknik pengumpulan data atas dokumendokumen berupa rekaman atas kejadian masa lalu yang dicetak dalam bentuk hard copi, sutar, buku, arsip, serta dokumen-dokumen lainnya.(Djam'an Satori dan Aan Komariah, 2014).

Metode analisa data yang digunakan dalam penelitian ini adalah metode analisa deskriptif kualitatatif, dengan mengunakan teknik triangulasi. Di mana triangulasi ini yaitu menggabungkan data dari sumber data dan tekhnik pengumpulan data yang telah ada.

\section{HASIL DAN PEMBAHASAN}

\section{Alasan yang Membentuk Pengetahuan dan Sikap Aparatur Negara terhadap Bank Syariah}

Salah satu yang mempengaruhi perkembangan dari bank syariah dengan melalui peningkatan strategi pelayanan ke nasabah ataupun calon nasabah. Strategi untuk melakukan pelayanan yang terbaik menjadi satu pilihan bilamana bank syariah ingin berkembang dan semakin tumbuh dari tahun ke tahun jumlah nasabahnya. Bank syariah yang merupakan lembaga bisnis, bukan lembaga kemanusiaan yang memaksa mau tidak mau harus memberikan yang terbaik untuk nasabah maupun masyarakat yang akan dijadikan nasabah dengan memberikan beberapa 
pengetahuan maupun penawaran yang terbaik yang bisa diberikan. Pembentukan persepsi akan memberikan dampak terhadap kemajuan bank syariah juga akan memberikan dampak terhadap kemajuan bank syariah sebagai lembaga keuangan. Persepsi dirasakan sangat penting, karena persepsi adalah sebuah proses saat individu mengatur dan menginterpretasikan kesan-kesan sensoris mereka guna memberikan arti bagi lingkungan mereka. Adapun alasan pengetahuan dan sikap aparatur sipil negara memilih mengunakan jasa bank syariah adalah sebagai berikut:

\begin{tabular}{|c|c|c|c|}
\hline No. & Alasan & Unit Analisa & Temuan \\
\hline \multirow[t]{2}{*}{1} & \multirow[t]{2}{*}{ product } & Penghimpunan data & $\begin{array}{ll}\text { - } & \text { Kurang variatif } \\
\text { - } & \text { Menyerupai produk konvensional } \\
\text { - } & \text { Belum banyak alternatif pilihan produk }\end{array}$ \\
\hline & & Pembiayaan & $\begin{array}{ll}- & \text { Akses yang masih sulit } \\
- & \text { Bagi hasil/magin yang masih tinggi } \\
- & \text { Syarat agunan seperti bank konvensional }\end{array}$ \\
\hline \multirow[t]{2}{*}{2} & \multirow[t]{2}{*}{ price } & $\begin{array}{l}\text { Biaya adm. DPK } \\
\text { Bagi hasil DPK }\end{array}$ & $\begin{array}{ll}\text { - } & \text { Cukup kompetitif } \\
\text { - } & \text { Cukup bersaing, rata-rata perbankan } \\
& \text { syariah memberikan bagi hasil yang tingi }\end{array}$ \\
\hline & & $\begin{array}{l}\text { Biaya Adm, } \\
\text { pembiayaan, } \\
\text { margin/bagi hasil }\end{array}$ & $\begin{array}{ll}\text { - } & \text { Cukup kompetitif } \\
\text { - } & \text { Relatif mahal, perbankan syariah } \\
& \text { menjual produk pembiayaan masih tingi. }\end{array}$ \\
\hline 3 & place & $\begin{array}{l}\text { Lokasi kantor dan } \\
\text { ATM }\end{array}$ & $\begin{array}{l}\text { - Jaringan kantor cabang pembantu belum } \\
\text { sebanyak perbankan konvensional }\end{array}$ \\
\hline \multirow[t]{2}{*}{4} & \multirow[t]{2}{*}{ promotion } & Materi promosi & 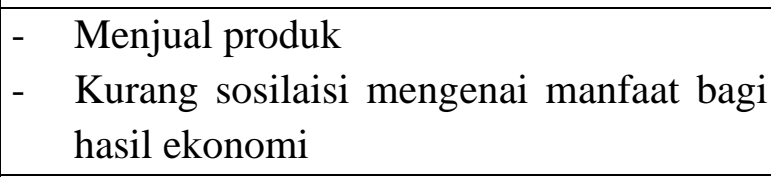 \\
\hline & & Media promosi & $\begin{array}{ll}\text { - } & \text { Menggunakan media cetak dan } \\
& \text { elektronok } \\
\text { - } & \text { Belum menggunakan jasa ulama sebagai } \\
& \text { duta perbankan syariah } \\
\text { - } & \begin{array}{l}\text { Belum memanfaatkan promosi dari } \\
\text { mulut ke mulut }\end{array}\end{array}$ \\
\hline 5 & people & Product knowladge & $\begin{array}{rlr}\text { - } & \text { Masih perlu peningkatan khususnya } \\
& \text { mengenai produk pembiayaan bagi hasil } \\
\text { - } & \text { Cukup produk } \\
& \text { funding/tabungan/deposito/ rekening giro }\end{array}$ \\
\hline
\end{tabular}




\begin{tabular}{|c|c|c|c|}
\hline & & & $\begin{array}{l}\text { dan lain-lain } \\
\text { - Peningkatan skill melalui training secara } \\
\text { rutin }\end{array}$ \\
\hline 6 & $\begin{array}{l}\text { Physical } \\
\text { evidence }\end{array}$ & $\begin{array}{l}\text { Bangunan fisik } \\
\text { kantor dan ATM }\end{array}$ & $\begin{array}{l}\text { - Kesan bangunan kantor bank syariah } \\
\text { masih kental khusus untuk masyarakat } \\
\text { muslim } \\
\text { - Area banking hall cukup nyaman } \\
\text { - Cukup aman dan nyaman }\end{array}$ \\
\hline 7 & Process & $\begin{array}{l}\text { Pengunaan } \\
\text { tekhnologi } \\
\text { informasi } \\
\text { sistem } \\
\text { oprasional }\end{array}$ & 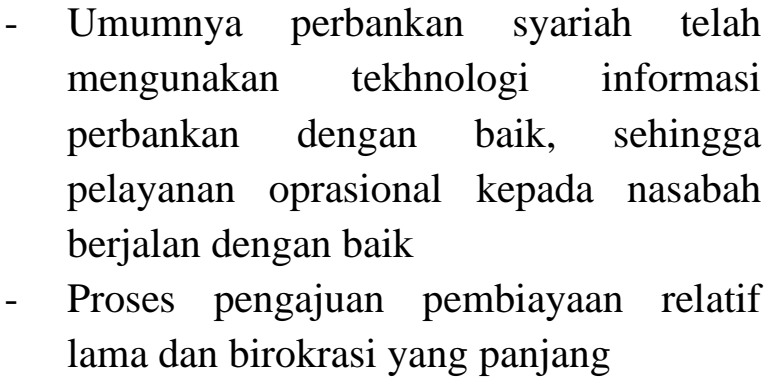 \\
\hline
\end{tabular}

2. Faktor-Faktor yang membentuk harus diperhatikan dalam rangka pengetahuan dan sikap Pegawai Aparaur Negara Terhadap Bank Syariah mengukur, merencanakan dan menerapakan strategi pengembangan

Faktor persepsi pegawai terhadap bank syariah adalah hal penting yang bank syariah di bidang apapun. Adapaun faktor-faktor tesebut adalah:

\begin{tabular}{|c|c|c|}
\hline No. & Unit analisis & Hasil analisis \\
\hline 1 & budaya & $\begin{array}{l}\text { a. Terbiasa dengan bank konvensional } \\
\text { b. Terikat dengan pekerjaan } \\
\text { c. Kenyamanan dan kemudahan berinteraksi melalui } \\
\text { bank konvensioanl }\end{array}$ \\
\hline 2 & sosial & $\begin{array}{l}\text { a. Adanya dorongan dari teman, keluarga dan lingkungan } \\
\text { b. Ingin mencoba-coba menggunakan bank syariah } \\
\text { c. Mau beda dari yang lain } \\
\text { d. Gaya hidup }\end{array}$ \\
\hline 3 & teknologi & $\begin{array}{l}\text { a. Penggunaan media dalam pengenalan bank syariah } \\
\text { tidak segencar bank konvensional } \\
\text { b. Belum maksimalnya bank syariah dalam promosi } \\
\text { produk melalui media visual, audio, internet media } \\
\text { sosial }\end{array}$ \\
\hline 4 & psikologis & $\begin{array}{l}\text { a. Brand image bank syariah belum menjadi jaminan } \\
\text { dalam menarik hati nasabah (pegawai ASN } \\
\text { b. Pemahaan pegawai bahwa bank syariah merupakan } \\
\text { bank konvensional yang diberi label syariah }\end{array}$ \\
\hline
\end{tabular}




\begin{tabular}{|l|l|l|}
\hline & $\begin{array}{l}\text { c. Pegawai dalam menabung mencari rasa aman dan } \\
\text { nyaman }\end{array}$ \\
\hline
\end{tabular}

\section{E. KESIMPULAN}

Pada dasarnya aparatur sipil negara memiliki persepsi terhadap jasa bank syariah dilihat dari pengetahuan dan sikap karena pelayanan yang diberikan bank syariah dan juga biaya administrasi yang ringan. Selain itu, pegawai mengetahui bahwa bank syariah bebas dari riba dan dalam bank syariah terdapat akad-akad yang dikenal dengan bagi hasil sehingga tidak merugikan dan memberatkan pihak yang melakukan akad.

Faktor persepsi pegawai aparatur negara dalam menggunakan jasa bank baik bank syariah tidak lepas dari busaya organisasi di mana pegawai tersebut bekerja. Utamanya pegawai aparatur sipil negara di kantor kementrian agama kabupaten lombok timur menggunakan jasa bak konvensional karena telah ada aturan dari atasan dalam penyeragaman rekening dalam penerimaan gaji pegawai, tetapi setalah mendapat gaji mereka ditransfer ke rekening bank syariah adapun pegawai yang menggunakan bank syariah hanya karena dorongan teman, keluarga dan lingkungan tempat tinggal bukan karena faktor religius dan sebagainya. Tampaknya brand image bank syariah tidak menjadi alternatif dalam menarik psikologi terhadap sikap pegawai aparatur sipil negara, begitupun dengan kemajuan tekhnologi sekarang ini tidak digunakan bank syariah sebagai sarana promosi produk-produk bank syariah.

\section{DAFTAR PUSTAKA}

Djam'an Satori dan Aan Komariah. (2014). Metodologi Penelitian Kualitatif. Alfabeta.

J. Moleong, L. (2017). Metode Penelitian Kualitatif. Bandung: PT Remaja Rosdakarya.

Nazir, M. (2011). Metode Penelitian. Bogor: Ghalia Indonesia.

Raco, J. . (2010). Metode Penelitian Kualitatif: Jenis, Karakteristik dan keunggulannya. Cikarang.

Sarwono Jonathan. (2006). Metodologi Penelitian Kuantitatif dan Kualitatif,. Yogyakarta: Graha Ilmu. 
